\title{
Investigation of Emotional Labor and Life Satisfaction Levels of Staff in Central Organization of General Directorate of Sports Services
}

\author{
Mehmet Gül ${ }^{1}$, Hüseyin Fatih Küçükibiş ${ }^{1}$ \\ ${ }^{1}$ The School of Physical Education and Sports, Sivas Cumhuriyet University, Sivas- Turkey \\ Correspondence: Mehmet Gül, The School of Physical Education and Sports, Sivas Cumhuriyet University, Sivas- \\ Turkey.
}

Received: February 2, 2019

Accepted: March 15, 2019

Online Published: March 19, 2019

doi:10.11114/jets.v7i3S.4153

URL: https://doi.org/10.11114/jets.v7i3S.4153

\begin{abstract}
Present study aims to investigate the emotional labor and life satisfaction levels of staff in the central organization of General Directorate of Sport Services. The population of the study consists of staff in the central organization of General Directorate of Sport Services. The sample is consisted of 276 staff determined by random sampling method. As data collection tool; to determine the demographic characteristics of the participants, a four-item "Personal Information Form" as well as a nine- item "Emotional Labor Scale" developed by Brotheridge and Lee (2003) and adapted to Turkish by Dursun et al. (2014) and "Life Satisfaction Scale" developed by Diener et al. (1985) and adapted to Turkish by Bekmezci and Mert (2013) were utilized in the study. In the analysis of the data, frequency, percentage (\%) and median values were used. Kruskal Wallis test was used for normal distribution of data and Mann Whitney U in test non-parametric tests was used according to the results gathered. The significance level was taken as $p<0,05$. When the findings obtained from the study were evaluated, life satisfaction levels of GDSS staff were at medium level. At the same time, there was a significant difference in education level and working time in the profession "in the sub-dimension of hidden emotions of emotional labor dimension of staff in GDSS. Activities such as various social activities can be organized by the Institution to improve the belonging of employees and to increase the levels of emotional labor and life satisfaction.
\end{abstract}

Keywords: sports, general directorate of sport services, emotional labor, life satisfaction

\section{Introduction}

It is expected from General Directorate of Sport Services (GDSS) to carry out public activities and public activities in the survival and dissemination of sports to meet the needs for sports services and to be in a position to combine sports with the community. It is possible to foresee that the employees of GDSS, which has an important and effective role in the development of the national sport, will be intertwined with all layers of society. In addition to the professional relationship, it is outstanding to improve the emotional and social motivation levels of the employees in establishing positive relations with the society which is the recipient of service. Studies on the employees of the sports services reaching from the lowest level to the highest level in GDSS and its practise to perform meticulously will contribute to increase the service quality and efficiency. The coordination of the central and provincial organizations will be formed by the impact of the emotional and life motivations that will be positive with the other units starting from the sub-units. It will be beneficial to carry out practices to increase the levels of emotional labor and life satisfaction of GDSS employees, to provide an appropriate working environment and to increase the satisfaction of service recipients.

The service providers demonstrate their labor in various aspects and the performance they perform determines the quality and level of the service. Currently, in addition to the physical and mental efforts of the employees of the service sector, their emotions have also become important. In the conditions of rising competition, the concept of emotional labor has come to the agenda and started to be discussed in order to ensure success (Yağciözen, 2017). Emotional efforts, in other words emotional labor of human resources have also emerged as another factor to be employed in occupational fields where one to one communication is intense (Basım and Beğenirbaş 2012). The concept of emotional labor is expressed as demonstration of the emotions demanded by the institution for the interaction with the recipients during the delivery of the service (Güngör, 2009). The purpose of emotional labor is defined as making service- recipients feel good or bad throughout the delivery of the service (Steinberg and Figart, 1999; Oğuz and Özkul 2016). Morris and 
Feldman, who regard emotional labor as an individual effort, expressed as "the individual effort, planning and control to reflect the emotions that the organization wants to be demonstrated in interpersonal interactions". and they stated that this effort was put forward by the service workers (Kurml and Geddes, 2000; Oğuz and Özkul 2016). It is possible to say that various life satisfaction and satisfaction situations are needed to stimulate the person in the emergence of emotional labor.

Life satisfaction expresses the situation that occurs with the comparisons between the individual's expectations and the situation faced. Life satisfaction involves the entire life of the person with different aspects. In other words, it defines the condition of satisfaction for all life, not any situation. Life satisfaction can be evaluated as an attitude when the life of individual is regarded as a conceptual assessment or judgement,(Özdevecioğlu, 2007). Rather than the subject defined on the individual from the outside, life satisfaction is evaluated in the subjective judgement of the individual (Cindiloğlu, 2016). Despite issues such as being healthy, being rich and happy marriage are important determiners of life satisfaction, it is not possible to be interpreted as being the same for all individuals (Pavot et al., 1993). Expression of satisfaction from the individual's life is the result of a subjective evaluation of the individual. In other words, life satisfaction is a summary of individual's liking or disliking parts (Heller et al., 2002).

The determination of life satisfaction is possible as a result of evaluations of all parts of life not just one part. The whole of family life, social life and of events affected permanently determine life satisfaction of the individual. Life satisfaction refers to the positive or negative judgement that is reached when individual's life is evaluated. In other words, rather than any part of the lives of individuals, they include a general view of their whole life (Saldaml1, 2008). This situation also includes the work life of the individual, which he spends most of the time.

The high level of life satisfaction of the individual gives ideas about work life. It is possible to say that the individual who has a high level of life satisfaction on a positive level is also happy in his business life. In parallel, life satisfaction can be seen in the same sense as" happiness concept". On the other hand, while life satisfaction is a component of subjective well-being, sometimes these two concepts can be used in the same sense. (Özdevecioğlu and Aktaş, 2007; Yılmaz et al., 2010). Happy individual at work can be expected to be happy in the life at the same level. In other words, the individual who is happy in his business life will be happy in his professional relations and transfer it to his life.

\section{Material and Method}

The study aiming to investigate the emotional labor levels and life satisfaction of the staff in the central organization of the General Directorate of Sport Services, is a descriptive model in the screening model. Screening models are research approaches aiming to describe a situation that exists in the past or the present. The event, the individual or the object, is tried to be defined as it is and within its own conditions (Karasar, 2005).

\section{Population and Sample}

The population of the study consists of the employees in the central organization of the General Directorate of Sport Services. The sample consisted of 276 people using random sampling method. The scales were applied to the sample group face-to-face.

\section{Data Collection Tool}

A four-item personal information form prepared by the researcher was used to determine the demographic characteristics of the study group consisted of the employees in General Directorate of Sport Services. As well as a nine- item "Emotional Labor Scale" developed by Brotheridge and Lee (2003) and adapted to Turkish by Dursun et al. (2014) and a five item "Life Satisfaction Scale" developed by Diener et al. (1985) and adapted to Turkish by Bekmezci and Mert (2013) were utilized in the study. It consists of three sub- dimensions: Emotional Labor Scale, False Emotions, In-depth Action and Hidden Emotions. Life Satisfaction Scale is a one-dimensional scale.

\section{Findings}

In this section, the findings of the distribution of the employees of the central organisation staff of GDSS according to demographic characteristics and findings on the levels of emotional labor and life satisfaction were included.

Table 1. Distribution of Participants According to Gender

\begin{tabular}{lll}
\hline Gender & Frequency & Percent \\
\hline Male & 164 & 59,4 \\
Female & 112 & 40,6 \\
Total & 276 & 100,0
\end{tabular}

Table 1 shows the distribution of the participants according to their gender of participants. According to Table 1, 164 
male $(59.4 \%)$ and 112 female $(40.6 \%)$ participants participated in the study.

Table 2. Distribution of Participants According to Age

\begin{tabular}{lll}
\hline Age (Year) & Frequency & Percent \\
\hline $\mathbf{2 5 -}$ & 18 & 6,5 \\
$\mathbf{2 6 - 3 5}$ & 136 & 49,3 \\
$\mathbf{3 6 - 5 0}$ & 104 & 37,7 \\
$\mathbf{5 1 +}$ & 18 & 6,5 \\
Total & 276 & 100,0
\end{tabular}

Table 2 shows the distribution of the participants according to their ages. According to Table 2 , it was found that 18 individuals were aged 25 and under and 51 and over (6.5\%) and on the other hand, the number of participants between 26-35 years of age was 136 (49.3).

Table 3. Distribution of Participants According to Educational Level

\begin{tabular}{lll}
\hline Education Level & Frequency & Percent \\
\hline High School and under & 59 & 21,4 \\
College & 29 & 10,5 \\
Undergraduate & 152 & 55,1 \\
Postgraduate & 36 & 13,0 \\
Total & 276 & 100,0
\end{tabular}

Table 3 presents the distribution of the participants according to education level. According to Table 3, it was found that 29 individuals were at the college level (10.5\%) while 152 participants at the undergraduate level.

Table 4. Distribution of Participants According to Working Time in Profession

\begin{tabular}{llll}
\hline $\begin{array}{l}\text { Working } \\
\text { (Year) }\end{array}$ & Time in Profession & Frequency & Percent \\
\hline $\mathbf{1 -}$ & & 38 & 13,8 \\
$\mathbf{2 - 4}$ & 98 & 35,5 \\
$\mathbf{5 - 1 0}$ & & 77 & 27,9 \\
$\mathbf{1 1 - 1 5}$ & 24 & 8,7 \\
$\mathbf{1 6 +}$ & & 39 & 14,1 \\
Total & & 276 & 100,0
\end{tabular}

Table 4 shows that $13.8 \%$ of the participants work for 1 year and lower, $35.5 \%$ for $2-4$ years, $27.9 \%$ for $5-10$ years, $8.7 \%$ for $11-15$ years, $14.1 \%$ of participants work for 16 years or more.

\section{Reliablity of the Data}

Table 5. Reliability of the scales used in the study according to Cronbach $\alpha$ coefficients

\begin{tabular}{llll}
\hline Scales & Factors & Item Numbers & $\begin{array}{l}\text { Cronbach Alpha Internal Consistency } \\
\text { Coefficient (a) }\end{array}$ \\
\hline Emotional & False Emotions & $1,2,3$ &, 794 \\
Labor Scale & In-depth Action & $4,5,6$ &, 822 \\
Life Satisfaction & Hidden Emotions & $7,8,9$ &, 682 \\
\hline
\end{tabular}

Table 5 shows that the data is reliable according to Cronbach $\alpha$ coefficients. First of all, reliability analysis was performed for each factor. Then the scale was found to be reliable by performing reliability analysis on all items used in the scale. 
Table 6. Median Test of Participants According to Working Years

\begin{tabular}{lllll}
\hline & False Emotions & In-depth Action & Hidden Emotions & Life Satisfaction \\
\hline $\mathbf{N}$ & 276 & 276 & 276 & 276 \\
Median & 2,0000 & 3,0000 & 2,6667 & 16,0000 \\
s.d. & 4 & 4 & 4 & 4 \\
$\mathbf{P}$ &, 063 &, 316 & $\mathbf{, 0 0 5}$ &, 724 \\
\hline
\end{tabular}

In Table 6, According to the findings of Median test in Table 6, while dimensions of Fake emotions, In-depth Action and Life satisfaction showed no significant difference, hidden emotions factor demonstrated significant difference $(\mathrm{M}=2,66$; $\mathrm{p}=, 005<0,05)$.

Mann Whitney U test presented in Table 7 was used to determine the difference between the study years of the hidden emotions factor which showed significant difference in Table 6.

Table 7. Mann Whitney U Test According to Working Year Of Participants

\begin{tabular}{lllllll}
\hline Factors & Working & Median & Sd & $\mathbf{Z}$ & $\mathbf{U}$ & $\mathbf{P}$ \\
\hline & $2-4$ & 2,33 &, 83 & $-2,369$ & 2990,500 & $\mathbf{, 0 1 8}$ \\
Hidden Emotions & $5-10$ & 3,00 &, 92 & & & \\
& $2-4$ & 2,33 &, 83 & $-2,429$ & 801,500 & $\mathbf{0 1 5}$ \\
& $11-15$ & 3,00 &, 93 & & & \\
& $11-15$ & 3,00 &, 93 & $-2,110$ & 320,500 & $\mathbf{0 3 5}$ \\
\hline $16+$ & 2,66 &, 72 & & &
\end{tabular}

When looked at the findings in Table 7, it is observed that the difference has a difference in the hidden emotion levels of 2- 4 working- year group and 5-10 working-year group. It is observed that the average of the 2-4 working- year group is 2.33 and of the 5-10 working- year group is 3 . According to the findings, it is observed that the level of emotion hidden of the 5-10 working year- group compared to the 2-4 working year- group is bigger.

The findings in Table 7 show that the hidden emotions factor has a difference the 2-4 working- year group and 11-15 working- year group. It is observed that the average of 2-4 working- year group is 2.33, and of the 11-15 working- year group is 3. According to the findings, it is observed that the level of hidden emotions by the group of 11-15 workingyears compared to the 2-4 working years' group is bigger.

The findings in Table 7 show that the hidden emotions factor has a difference in the 11-15 working years' group and 16 and more working- year group. It is observed that the average of the group of 11-15 working- year is 3 , the average of 16 and more working- year group is 2.66. According to the findings, it is determined that the level of hidden emotion of 11-15 working- year is higher than group of 16and more working- year.

When the study findings are examined generally, it is observed that the groups that have lower working years hide their feelings less and they hide their feelings more as the working year increases.

Table 8. Median Test According to Educational Levels of Participants

\begin{tabular}{lllll}
\hline & False Emotions & In-depth Action & Hidden Emotions & Life Satisfaction \\
\hline $\mathbf{N}$ & 276 & 276 & 276 & 276 \\
Median & 2,0000 & 3,0000 & 2,6667 & 16,0000 \\
s.d. & 3 & 3 & 3 & 3 \\
$\mathbf{P}$ &, 908 &, 454 & $\mathbf{0 3 5}$ &, 322 \\
\hline
\end{tabular}

According to the findings of Median test in Table 8, False Emotions Duy, In-depth Action, Life Satisfaction showed no significant difference but Hidden Emotions factor has a significant difference $(M=2,66 ; p=, 035<0,05)$.

Mann Whitney $U$ test was performed in Table 9 to determine which working years have difference in the hidden emotions factor found in Table 8.

Table 9. Mann Whitney U Test According to Educational Level of Participants

\begin{tabular}{|c|c|c|c|c|c|c|}
\hline Factors & Education & Median & Sd & $\mathbf{Z}$ & $\mathbf{U}$ & $\mathbf{P}$ \\
\hline 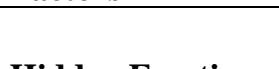 & $\begin{array}{l}\text { High School } \\
\text { and lower }\end{array}$ & 2,66 & ,96 & \multirow{2}{*}{$-2,010$} & \multirow{2}{*}{802,000} & \multirow{2}{*}{,044 } \\
\hline motions & Postgraduate & 2,33 & ,78 & & & \\
\hline
\end{tabular}

When the findings of Table 9 are examined, it is seen that the Hidden Emotions factor levels have a difference in the education groups of high school and lower and post-graduate levels. It is observed that the average of high school and 
lower working year group is 2.66 and the average of the post-graduate education group is 2.33 . According to the findings, it is observed that the high school and the lower education group has higher level of hidden emotion than post-graduate education group.

When the findings of the study are examined, it is observed that the group with lower education level has higher levels of hidden emotions than those with a high level of education.

\section{Discussion and Conclusion}

In this section of the study, the findings of the analysis are discussed in the context of the related literature.

A total of 276 GDSS employees took part in the study. According to the descriptive statistics for the demographic characteristics of the participants; $59.4 \%$ of the participants were male (Table 1). $49.3 \%$ of these participants were between 26-35 years (Table 2) and 35.5\% were between 2-4 years working individuals (Table 4).

In the dimension of emotional labor, The sub-dimension of False Emotions and In-depth Action, Emotional labor dimension in the sub-dimension of hidden emotions of the working personnel in GDSS differs according to the variable of working time in the profession. When the study findings are examined in general, it is observed that the groups that have less working year hide their feelings and emotions less and hide more as the working year increases (Table 7). In the study conducted by Seçer and Tinar (2004), no differences were found in the dimensions of emotional labor depending on the demographic characteristics of the sample, such as working time in the profession. It does not show any similar with the findings of the study. On the other hand, Oral and Köse's (2011) study did not show any significant difference in terms of working time in the present workplace. This result is not similar to the sub-dimensions of the hidden emotions of the study. However, according to the results obtained by Oral and Köse (2011), the findings of Emotional Labor dimension False Emotions and In-depth Action sub-dimensions are similar in this study. There was no difference in the life satisfaction of the employees according to the working years in the profession (Table 6). The study conducted by Seçkin and Çoban (2017) showed that the life satisfaction of the individuals who participated in the study did not have any relationship with their working time. It is possible to say that this situation is similar to this study.

In the emotional labor dimension of the staff in GDSS, no difference was found in the dimension of life satisfaction and the sub-dimension of False Emotions and In-depth Action according to education levels of participants (Table 8). However, the emotional labor dimension of the working staff differs according to the variable of sub-dimension of Hidden Emotions according to education levels. It is observed that this difference is between the high school and lower education and the post-graduate education groups. According to the findings, it is observed that the level of hidden emotions by the group of high school and the lower education is higher than the post-graduate education group (Table 9). When the study findings were examined in general, it was found that the group with lower levels of education had higher levels of hidden emotions than those with a high education level. In the study conducted by Seçer and Tinar (2004), no differences were found in the dimensions of emotional labor depending on the demographic characteristics of the sample's educational levels. It is not similar to the findings of the study.

There was no difference in the life satisfaction dimension of the employees according to their education levels (Table 8). The study conducted by Seçkin and Çoban (2017) showed that the life satisfaction of the individuals who participated in the study was not related to their educational levels. It can be concluded that this situation is similar to present study.

As a result, it was determined that the employees' emotional labor and life satisfaction levels were at average level. On the other hand, some differences in the sub-dimension of hidden emotion factor in the emotional labor were found according to their working time and educational levels.

In parallel with these results, it is recommended to increase the in-service training of the employees in order to decrease the emotional labor levels of the employees and to increase the life satisfaction levels of the employees and to provide the working environments in which the views of all employees are taken into consideration equally.

\section{References}

Basım, H. N., \& Beğenirbaş M. (2012). Emotional Labor in Work Life: A Study of Scale Adaptation. Journal of Management and Economics, 19(1), 77-90.

Bekmezci, M., \& Mert, İ.S. (2013). Turkish Validity and Reliability Study of Life Satisfaction Scale. Toros University Journal of Social Sciences, 8, 166-177.

Brotheridge C. M., \& Lee R. T. (2003), Development and validation of the Emotional Labour Scale, Journal of Occupational and Organizational Psychology, 76, 365-379. https://doi.org/10.1348/096317903769647229

Cindiloğlu, M. (2016). The role of commitment focus on the effect of leadership on job and life satisfaction, Master Thesis. Gaziosmanpaşa University Social Sciences Institute. Tokat/ Turkey 
Diener, E., Emmons, R. A., Larsen, R. J., \& Griffin, S. (1985). The Satisfaction with Life Scale. Journal of Personality Assessment, 49, 71-75. https://doi.org/10.1207/s15327752jpa4901_13

Dursun, S., Aytaç, S., \& Bayram, N. (2014). Validity and reliability study of Turkish version of Emotional Labor Scale. ISGUC The Journal of Industrial Relations and Human Resources, 16(3), 10-18. https://doi.org/10.4026/1303-2860.2014.0252

Güngör, M. (2009). The Phenomenon of Emotional Labour: Process and Outcomes. Journal of Kamu-Iş, 1(1), 167-184.

Heller, D. T., Judge, A., \& Watson, D. (2002). The Confounding Role of Personality and Trait Affectivity in The Relationship Between Job and Life Satisfaction, Journal of Organizational Behavior, 23, 815-835. https://doi.org/10.1002/job.168

Karasar, N. (2005). Scientific Research Method (17. Edition). Ankara: Nobel Broadcasting Distribution, 81-83.

Kurml, S. M., \&Geddes, D. (2000). Exploring the dimensions of emotional labor: Hochschild's work, Management Communication Quarterly, 14, 8-49. https://doi.org/10.1177/0893318900141002

Oğuz, H., \& Özkul, M. (2016) A Study On Emotional Labor Sociological Factors Shape The Process: The Implementation West Mediterranean. Suleyman Demirel University The Journal of Visionary, 7(16), 130-154. https://doi.org/10.21076/vizyoner.265476

Oral, L., \& Köse, S. (2011). A Research on Phsicians' Use of Emotional Labor and The Relationship Between Their Job Satisfaction And Burnout Levels. Süleyman Demirel University the Journal of Faculty of Economics and Administrative Sciences, Vol.16, No.2, pp.463-492.

Özdevecioğlu, M., \& Aktaş, A. G. A. (2007). The Effects of Career Commitment, Occupational Commitment and Organizational Commitment on LiFe Satısfaction: The Role of Work-Family Conflict. Erciyes University Faculty of Economics and Administrative Sciences Journal, (28), 1-20.

Pavot, W., \& Diener, E. (1993). Review of the satisfaction with life scale. Psychological Assessment, 5(2), 164-172. https://doi.org/10.1037/1040-3590.5.2.164

Saldaml, A. (2008). Study on Determining The Job And Life Satisfactıon of Department Supervisors Working in Hotel Enterprises. Marmara University Journal of Economic and Administrative Sciences, 25(2): 693-719.

Seçer, Ş., \& Tinar, M. Y., (2004). Emotional Labor as a Source of Burnout at Work: A Study on Nurses, 9. National Ergonomics Congress. Denizli.

Seçkin, Ş. N., \& Çoban, R. (2017). The Moderating Effect of Perceived Alternative Job Opportunities on Pay Level Satisfaction, Intention to Remain and Life Satisfaction Relationship. Journal of Business Research Turk, 9(3), 134-148. https://doi.org/10.20491/isarder.2017.292

Steinberg, J. R., \& Figart, D. M. (1999). Emotinal Labor Since The Managed Heart, ANNALS, AAPSS, 561, 8-25.

Yağciözen, M., (2017). Emotional labor in healthcare staff, analysis of exhaustion and job satisfaction relationship: an application in the province of Konya. Master Thesis. Necmettin Erbakan University Health Sciences Institute. Konya.

Yılmaz, G., Keser, A., \& Yorgun, S. (2010). The Impact of Job Satisfaction on Life Satisfaction and Intention to Leave Among Unionized Lodging Sector Employees. PARADOKS, Journal of Economics, Sociology and Policy, 6(1), $87-107$.

\section{Copyrights}

Copyright for this article is retained by the author(s), with first publication rights granted to the journal.

This is an open-access article distributed under the terms and conditions of the Creative Commons Attribution license which permits unrestricted use, distribution, and reproduction in any medium, provided the original work is properly cited. 